\title{
Value at risk, outliers and chaotic dynamics
}

\author{
C. Kyrtsou $^{1} \&$ V. Terraza ${ }^{2}$ \\ ${ }^{1}$ University of Macedonia, Department of Economics, Greece \\ ${ }^{2}$ CREFI-LSF, University of Luxembourg, Luxembourg
}

\begin{abstract}
Financial returns series typically exhibit excess kurtosis and volatility clustering. The GARCH is often applied to describe these two stylized facts. Nevertheless, all excess kurtosis in stock returns cannot be captured by this model. In presence of such dynamics, a non-linear model in variance cannot take into account all the non-linearity in returns. The aim of this work is the study of relationships between chaotic dynamics, and outliers as well as their impact on Value at Risk. In this paper, our empirical study is based on the daily Nikkei returns series from $06 / 01 / 1987$ to $14 / 03 / 2001$. We apply the traditional GARCH and the MackeyGlass-GARCH (Kyrtsou and Terraza (2003)) both to the initial and the filtered Nikkei returns series without outliers. The performance test of Lopez (1988) for Value at Risk models is then applied to determine the best model. We show that during the period of estimation, the GARCH and the Mackey-Glass-GARCH VaR models with (without) outliers at $95 \%$ overestimate (underestimate) risks. The filtering of outliers lead to underestimation of risk more accentuated during the Asian crisis period confirming the presence of severe distortions in the underlying structure of the series when removing extreme events. During this period, the Mackey-Glass-GARCH is better than the GARCH comparing the hedging rates.
\end{abstract}

Keywords: GARCH model, Mackey-Glass GARCH model, Value at Risk, outliers.

\section{Introduction}

The new regulations on banking supervision gave new dimensions in the application of Value-at-Risk (VaR) technique. During the last 10 years, VaR measures as well as its parametric estimation based on the volatility of stock returns have been considered as the standard measure of risk $[1,7,21,22,23]$. 
Recent studies have shown the temporal dependence of squared returns. To capture this type of dependence, different variants of ARCH models have been used. The Riskmetrics system proposed by the JP Morgan Bank (1996) could eventually explain the popularity of the traditional stochastic approach using an IGARCH process without constant to model the variance. However, Pafka and Kondor [21] provided evidence that this model is inadequate to describe volatility behaviour. Even if alternative models have been proposed to estimate the Value at Risk (PGARCH, APARCH), the strong remaining structure in the standardised residuals is a proof that pure stochastic models cannot isolate and filter complex underlying dynamics. The discovery of high-dimensional chaotic dynamics has changed our point of view on the source of financial fluctuations and excessive returns. Financial markets are governed by more complicated and richer dynamics. In an uncertain and volatile world, assumptions about rational and homogenous investors, linear incorporation of the information into stock prices, and pure stochastic nature of fluctuations cannot hold out against critics. We think that a mixed theory containing both endogenous and exogenous explanations of the observed anomalies would be more rational and realistic. Recent empirical works on noisy chaos of Kyrtsou and Terraza [15,16] Kyrtsou and Labys [10,11], Kyrtsou and Serletis [12], Kyrtsou et al. [13] have revealed the existence of chaotic structures in the mean of macroeconomic and financial returns series. The interactions between endogenous and exogenous forces in the market lead to complex dynamics that are incorporated into prices. Financial returns series typically exhibit excess kurtosis and volatility clustering. That is, large observations occur more often than one might expect for a normally distributed variable. The GARCH model often applied to describe these two stylized facts cannot capture all excess kurtosis and high Jarque-Bera. This is mainly due to the fact that some outliers or extreme values contaminate series so that the conditional distribution looks heavy tailed. Some researches suggested to correct the data for outliers when using GARCH models (Franses and Ghijsels [4], Van Dijk et al [2]. They found that neglecting outliers could erroneously suggest misspecification or inadequate descriptive models for financial modeling. However, outliers can be the result of the system behaviour itself and as a structural attribute its removal can destroy valuable information in the underlying generating mechanism (Kyrtsou [9]). In that case treating outliers only as an exogenous distortion of the series can deteriorate the explicative power of the modelling.

The aim of this work is the study of relationships between chaotic dynamics, and outliers as well as their impact on Value at Risk. Theoretical conclusions of Kyrtsou and Malliaris [14] on the removal of outliers find their application here. In this paper we compare the traditional VaR-GARCH with the VaR-MackeyGlass-GARCH modeling both to the initial and the filtered NIKKEI returns series i.e. the series where outliers have been removed.

\section{Methodology and empirical results}

The economic market behaviour is governed by complex dynamical systems, which are typically marked by interactions and feedbacks between their 
components or subsystems. These feedbacks can efficiently be described by a time-delayed self-interaction of the subsystems. The resulting delayed feedback dynamics have been modelled successfully by delay equations.

\subsection{Noisy chaotic dynamics and outliers}

Well-known example of non-linear equation is the Mackey-Glass process (discrete version) [19]:

$$
\mathrm{X}_{\mathrm{t}}=\mathrm{a} \frac{\mathrm{X}_{\mathrm{t}-\tau}}{1+\mathrm{X}_{\mathrm{t}-\tau}^{\mathrm{c}}}-\delta \mathrm{X}_{\mathrm{t}-1}
$$

The choice of lags $\tau$ and $c$ in eqn. (1) is crucial since determine the dimensionality of the system. Kyrtsou and Terraza [16] have developed a stochastic version of the deterministic Mackey-Glass model, where the error term is supposed to follow an ARCH(1) process.

$$
\mathrm{X}_{\mathrm{t}}=\mathrm{a} \frac{\mathrm{X}_{\mathrm{t}-\tau}}{1+\mathrm{X}_{\mathrm{t}-\tau}^{\mathrm{c}}}-\delta \mathrm{X}_{\mathrm{t}-1}+\varepsilon_{\mathrm{t}}
$$

where: $\varepsilon_{t} \mid I_{t} \sim N\left(0, h_{t}\right)$ with $h_{t}$ the conditional variance

$$
\mathrm{h}_{\mathrm{t}}=\alpha_{0}+\alpha_{1} \varepsilon_{\mathrm{t}-1}^{2}+\beta_{1} \mathrm{~h}_{\mathrm{t}-1}
$$

This chaotic model is interesting because of its similarity to economic and financial series; it is non-linear in mean and variance. The economic data look rather random and show weak significance of low-dimensional non-linear dynamics. They are the outcome of a high-dimensional (noisy chaotic) attractor produced by a more or less simple delayed feedback system. The subtraction of the detected outliers (outliers are identified using the Freedman et al. definition. (Freedman, D., Pisani, R., and Purves, R., (1978): Statistics, New York: W.W. Norton)) from the initial returns series gives the filtered series. The GARCH and the Mackey-Glass-GARCH will be applied both to the Nikkei and the filtered returns series.

\subsection{Empirical analysis}

First, we carry out a preliminary analysis showing the existence of linear and non-linear structures in the daily Nikkei returns series (from 06/01/1987 to 14/03/2001). The series is widely asymmetric with skewness $=-0.142$ and leptokurtic with kurtosis=12.205, i.e. non-normal with Jarque-Bera $=13084.83$. Several other tests for general and neglected non-linearity are used i.e. White [26], Theiler et al. [24], Hinich [5,6], McLeod-Li [20], Engle [3] and Tsay [25] tests (see Kyrtsou and Terraza [17]). Hereafter, we use dlnikkei for the initial returns and adlnikkei for the filtered returns. For presentation purposes, obtained results are not reported here. They are however available upon request. Running the tests for non-linearity lead to the conclusion that the dlnikkei series is nonlinear in mean and variance while the adlnikkei series is non-linear only in variance. 
In the aim to identify the hidden dynamics causing abnormal returns and likely extreme observations we will employ a Mackey-Glass-GARCH process. The results from the estimations of the benchmark simple GARCH and the new chaotic GARCH models are given in tables 1 and 2 for the dlnikkei series and in tables 3 and 4 for the adlnikkei series.

Table 1: $\quad$ The Mackey-Glass-GARCH model (dlnikkei).

\begin{tabular}{ccc}
\hline Coefficient & Value & t-Statistic \\
\hline $\mathrm{a}$ & 13.02 & $1.68^{*}$ \\
\hline$\delta$ & 12.98 & $1.68^{*}$ \\
\hline$\alpha_{0}$ & $5.38 \mathrm{e}-06$ & $2.84^{* *}$ \\
\hline$\alpha_{1}$ & 0.169 & $3.129^{* *}$ \\
\hline$\beta_{1}$ & 0.827 & $18.99^{* *}$ \\
\hline Standardized residuals & Kurtsosis $=11.92$ & Jarque-Bera $=12461.53$ \\
\hline
\end{tabular}

* Significant at $10 \%, * *$ significant at $5 \%$.

Table 2: $\quad$ The GARCH model (dlnikkei).

\begin{tabular}{ccc}
\hline Coefficient & Value & t-Statistic \\
\hline$\alpha_{0}$ & $4.10 \mathrm{e}-06$ & $2.65^{*}$ \\
\hline$\alpha_{1}$ & 0.136 & $3.04^{*}$ \\
\hline$\beta_{1}$ & 0.857 & $23.21^{*}$ \\
\hline Standardized residuals & Kurtsosis $=13.31$ & Jarque-Bera $=16671.37$
\end{tabular}

* Significant at $5 \%$.

Table 3: $\quad$ The Mackey-Glass-GARCH model (adlnikkei).

\begin{tabular}{ccc}
\hline Coefficient & Value & t-Statistic \\
\hline $\mathrm{a}$ & 0.022 & 0.84 \\
\hline$\delta$ & 0.011 & 0.59 \\
\hline$\alpha_{0}$ & $1.13 \mathrm{e}-06$ & $3.14^{*}$ \\
\hline$\alpha_{1}$ & 0.066 & $7.23^{*}$ \\
\hline$\beta_{1}$ & 0.928 & $92.89^{*}$ \\
\hline Standardized residuals & Kurtsosis $=3.92$ & Jarque-Bera $=134.13$ \\
\hline
\end{tabular}

* Significant at $5 \%$.
Table 4: $\quad$ The GARCH model (adlnikkei).

\begin{tabular}{ccc}
\hline Coefficient & Value & t-Statistic \\
\hline$\alpha$ & 1.17 e-06 & $3.22^{*}$ \\
\hline$\alpha_{1}$ & 0.066 & $7.23^{*}$ \\
\hline$\beta_{1}$ & 0.927 & $92.13^{*}$ \\
\hline Standardized residuals & Kurtsosis $=3.92$ & Jarque-Bera $=134.76$ \\
\hline Significant at $5 \%$. & &
\end{tabular}


Comparing the results, outliers filtering seems to diminish the sample statistics of the standardized residuals. Justifying the absence of non-linearity in mean based on the inexistence of outliers is not as simple as it looks. Recent empirical works show that similar results can be spurious due to the distortions induced by the removal procedure of outliers. Certainly we cannot deny the possibility that the dynamics, which are modelled by the feedback-trading rule of the mean chaotic equation, are part of the underlying forces producing sudden changes in market prices. However the fact that eliminating extreme events removes important information should make us more cautious about accepting similar statements. One we need in order to cross-validate such an assumption is to estimate risk on the filtered series and then check if improvements are achieved. This issue will be addressed in the next section.

\section{Performance tests for value at risk models}

To test the performance of VaR models in the binomial approach, the number of failures or exceptions is counted on the observation period, and then expected returns are compared with estimations of VaR. If, the loss exceeds the amount of the VaR, an exception is observed. In fact, the test is based on a binary measure from an indicator variable noted $\mathrm{I}_{\mathrm{t}}$.

We use the Lopez [18] test:

$$
I_{t}=\left\{\begin{array}{l}
1+\left(r_{i, t+1}-V a R_{i, t}\right)^{2} \\
0 \quad \text { otherwise }
\end{array} \quad \text { if } \quad r_{i, t+1} \prec V a R\right.
$$

The number of exceptions divided by the observation period defines the failure rate. This ratio compared with the probability of the VaR model gives the proportion of times where the VaR amount is exceeded. From this measure, a hedging index may be constructed to facilitate the interpretations of results.

\subsection{The dlnikkei series}

In Tables 5 and 6 we report the number of exceptions, the failure rate and the hedging index of the VaR GARCH and the VaR Mackey-Glass-GARCH models at $95 \%$. More precisely, for each sample, we show overestimations of risks. The obtained results show that on average the models hedge the negative losses, since the hedging index is $95 \%$ for the GARCH model and equal to $95.2 \%$ for the Mackey-Glass-GARCH model.

Table 5: $\quad$ Number of exceptions at 95\% for the GARCH (dlnikkei).

\begin{tabular}{|c|c|c|c|c|}
\hline Samples & $\begin{array}{c}\text { Observed } \\
\text { Exceptions }\end{array}$ & $\begin{array}{c}\text { Expected } \\
\text { exceptions }\end{array}$ & $\begin{array}{c}\text { Failure } \\
\text { rate }\end{array}$ & $\begin{array}{c}\text { Hedging } \\
\text { index }\end{array}$ \\
\hline All the period & 186 & 185 & 0.050 & 0.95 \\
\hline $06 / 01 / 1987-31 / 12 / 1990$ & 42 & 52 & 0.040 & 0.96 \\
\hline $01 / 01 / 1991-30 / 12 / 1994$ & 51 & 52 & 0.048 & 0.952 \\
\hline $\mathbf{0 1 / 0 1 / 1 9 9 5 - 3 1 / 1 2 / 1 9 9 8}$ & 65 & 52 & 0.062 & $\mathbf{0 . 9 3 8}$ \\
\hline $01 / 01 / 1999-14 / 03 / 2001$ & 28 & 29 & 0.048 & 0.952 \\
\hline
\end{tabular}


One exception appears in bold, the period from $01 / 01 / 95$ to $31 / 12 / 1998$, which includes the Asian crisis 1997--1998. During this period, the Value at Risk is underestimated, and so our models are not valid. However, the MackeyGlass-GARCH gives the best estimations of the hedging rate (94.1\%) against $93.8 \%$ for the GARCH model. So, it seems that the noisy chaotic model is able to take into account extreme risks occurring over volatile periods (crises).

Table 6: Number of exceptions at $95 \%$ for the Mackey-Glass-GARCH (dlnikkei).

\begin{tabular}{|c|c|c|c|c|}
\hline Samples & $\begin{array}{c}\text { Observed } \\
\text { Exceptions }\end{array}$ & $\begin{array}{c}\text { Expected } \\
\text { Exceptions }\end{array}$ & $\begin{array}{c}\text { Failure } \\
\text { rate }\end{array}$ & $\begin{array}{c}\text { Hedging } \\
\text { index }\end{array}$ \\
\hline All the period & 177 & 185 & 0.048 & 0.952 \\
\hline $06 / 01 / 1987-31 / 12 / 1990$ & 42 & 52 & 0.040 & 0.96 \\
\hline $01 / 01 / 1991-30 / 12 / 1994$ & 49 & 52 & 0.047 & 0.953 \\
\hline $\mathbf{0 1 / 0 1 / 1 9 9 5}-\mathbf{3 1 / 1 2 / 1 9 9 8}$ & 62 & 52 & 0.059 & $\mathbf{0 . 9 4 1}$ \\
\hline $01 / 01 / 1999-14 / 03 / 2001$ & 24 & 29 & 0.041 & 0.959 \\
\hline
\end{tabular}

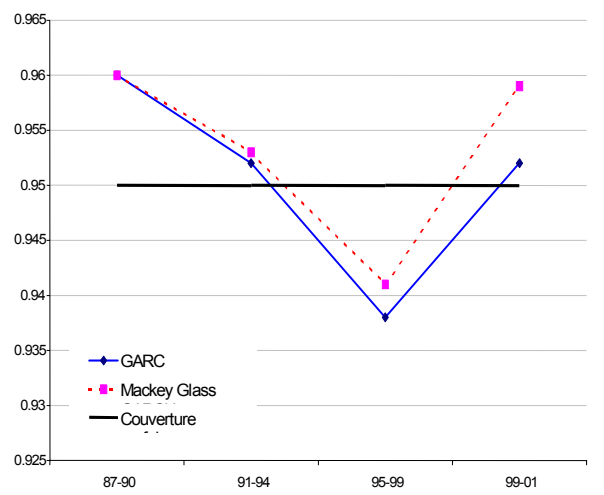

Figure 1: Hedging indexes.

Comparing the number of observed exceptions in Tables 5 and 6 , it is obvious that the Mackey-Glass-GARCH model outperforms the simple GARCH model. This means that within periods where exceptional risks are observed, the noisy chaotic approach can be more efficient than the traditional stochastic. This conclusion is concretised in figure 1 .

As we can see there are under-hedge periods where the probability is inferior to $95 \%$. From $06 / 01 / 1987$ to $14 / 03 / 2001$, on average, risks are overestimated at 95\%. Similar results have been obtained in Alexander and Leigh [1]. They provided evidence that the ARCH type models (particularly the Riskmetrics model) are generally accepted at $95 \%$. 


\subsection{The adlnikkei series}

The second stage of our analysis is to repeat the same procedure this time for the adlnikkei series (without outliers). Tables 7 and 8 give the number of exceptions at $95 \%$ for both models.

The conclusions are quite different comparing Tables 5, 6 and 7, 8. The VaR is underestimated at $95 \%$ by the two models, even more in the case of the Mackey-Glass-GARCH model. More precisely, for each sample, there are no significant differences concerning the number of exceptions between the two models. During the period of crisis (01/01/1995 to 31/12/1998), hedging index is equal to $94 \%$ and $93.7 \%$ for the GARCH and the Mackey-Glass-GARCH models respectively. An important characteristic is that figures 1 and 2 keep the same shape.

Table 7: Number of exceptions at $95 \%$ for the GARCH model (adlnikkei).

\begin{tabular}{|c|c|c|c|c|}
\hline Samples & $\begin{array}{c}\text { Observed } \\
\text { Exceptions }\end{array}$ & $\begin{array}{c}\text { Expected } \\
\text { exceptions }\end{array}$ & $\begin{array}{c}\text { Failure } \\
\text { rate }\end{array}$ & $\begin{array}{c}\text { Hedging } \\
\text { index }\end{array}$ \\
\hline All the period & $\mathbf{2 1 2}$ & $\mathbf{1 8 5}$ & $\mathbf{0 . 0 6 4}$ & $\mathbf{0 . 9 3 6}$ \\
\hline $06 / 01 / 1987-31 / 12 / 1990$ & 52 & 52 & 0.05 & 0.95 \\
\hline $01 / 01 / 1991-30 / 12 / 1994$ & 63 & 52 & 0.060 & 0.940 \\
\hline $\mathbf{0 1 / 0 1 / 1 9 9 5 - 3 1 / 1 2 / 1 9 9 8}$ & 66 & 52 & 0.064 & $\mathbf{0 . 9 3 6}$ \\
\hline $01 / 01 / 1999-14 / 03 / 2001$ & 31 & 29 & 0.030 & 0.97 \\
\hline
\end{tabular}

Table 8: Number of exceptions at $95 \%$ for the Mackey-Glass-GARCH model (adlnikkei).

\begin{tabular}{|c|c|c|c|c|}
\hline Samples & $\begin{array}{c}\text { Observed } \\
\text { Exceptions }\end{array}$ & $\begin{array}{c}\text { Expected } \\
\text { exceptions }\end{array}$ & $\begin{array}{c}\text { Failure } \\
\text { rate }\end{array}$ & $\begin{array}{c}\text { Hedging } \\
\text { index }\end{array}$ \\
\hline All the period & 214 & 185 & 0.057 & 0.943 \\
\hline $06 / 01 / 1987-31 / 12 / 1990$ & 52 & 52 & 0.05 & 0.95 \\
\hline $01 / 01 / 1991-30 / 12 / 1994$ & 63 & 52 & 0.061 & 0.938 \\
\hline $\mathbf{0 1 / 0 1 / 1 9 9 5 - 3 1 / 1 2 / 1 9 9 8}$ & 67 & 52 & 0.065 & $\mathbf{0 . 9 3 5}$ \\
\hline $01 / 01 / 1999-14 / 03 / 2001$ & 31 & 29 & 0.030 & 0.97 \\
\hline
\end{tabular}

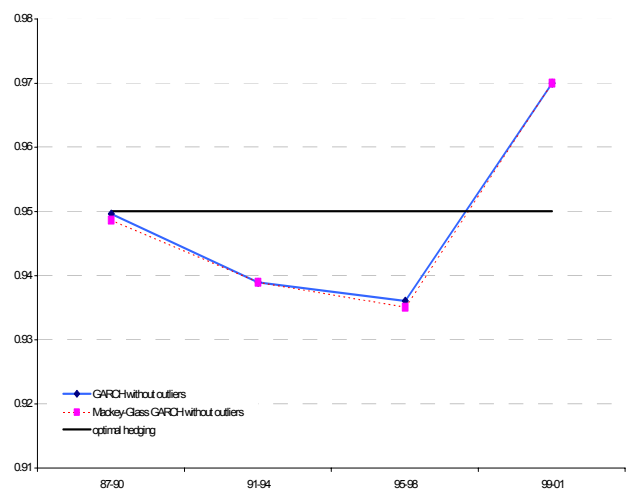

Figure 2: Comparison of hedging indexes. 


\section{Conclusion}

The use of a Mackey-Glass-GARCH model for filtering non-linear structures in stock series can reduce the potential informational bias in the estimation of risk involving underestimation of risk (during crises period). Indeed, extreme risks come from both heterogeneous behaviors of agents and external events. GARCH models are not sufficient for taking into account these two risk sources. Interactions between endogenous and exogenous dynamics in financial returns contain information that is valuable for risk estimation.

Furthermore, it seems that the removal of extreme observations is not the solution to the problem of risk overestimation. During extreme events, the removal of outliers calls into question the $\mathrm{VaR}$ methodology. Important characteristics of the nature of shocks can be lost. This result is quite evident since as Kyrtsou [9] underlines: "removal (of outliers) may lead to serious distortions of the structure of the signal". In turn, the filtering of highdimensional structures employing the Mackey-Glass-GARCH directly on the initial returns series improves the estimation of risk. Other financial applications on market indexes are needed to comfort our results. Technically, an eventual extension of the present paper could concern further investigation of alternative high-dimensional chaotic schemas and their impact on VaR calculation. These works will be presented in the near future.

\section{References}

[1] Alexander C.O, Leigh C.T., (1997): On the covariance matrices used in value at risk models, Journal of Derivatives pp. 50-62 spring 1997

[2] Dijk DJC Van, Franses PH HBF, Lucas A., (1999): testing for smooth transition non linearity in the presence of outliers, Journal of Business and Economic Statistics 17(2), pp. 217-235.

[3] Engle R.F., (1982): Autoregressive conditional heteroskedasticity with estimates of the variance of United Kingdom inflation, Econometrica, vol.50, nº pp.987-1007.

[4] Franses PH HBF, Ghijsels H., (1999): Additive outliers, GARCH and forecasting volatility, International Journal of Forecasting, 15 pp 1-9.

[5] Hinich M.J., (1982): Testing for Gaussianity and linearity of a stationary time series, Journal of Time Series Analysis, vol.3, n¹, pp. 169-176.

[6] Hinich, M. Patterson, D.M., (1995): Detecting epochs of transient dependence in white noise, Working Paper, University of Texas at Austin.

[7] Jorion P (1997): Value at risk: The new benchmark for controlling market risk, McGraw - Hill.

[8] JP Morgan (1996): Riskmetrics: technical document.

[9] Kyrtsou C., (2008): On the role of complexity in economic time series: New evidence for the crude oil and Gasoline price series relationship, accepted under revisions, Energy Economics. 
[10] Kyrtsou C., Labys W., (2006): Evidence for chaotic dependence between US inflation and commodity prices, Journal of Macroeconomics, 28(1), pp. 256-266.

[11] Kyrtsou C., Labys W., (2007): Detecting positive feedback in multivariate time series: the case of metal prices and US inflation, Physica A, 377(1), pp. 227-229.

[12] Kyrtsou C., Serletis A., (2006). Univariate tests for nonlinear structure, Journal of Macroeconomics, vol. 28, 1, 154-168

[13] Kyrtsou C., Labys W., Terraza M., (2004): Noisy chaotic dynamics in commodity markets, Empirical Economics, 29 (3), pp. 489-502.

[14] Kyrtsou C., Malliaris A., (2008): The impact of information signals on market prices, when agents have non-linear trading rules, Economic Modelling, accepted subject to revisions.

[15] Kyrtsou C., Terraza M., (2002): Stochastic chaos or ARCH effects in stock series? A comparative study, International Review of Financial Analysis, vol.11, n4, pp.407-431.

[16] Kyrtsou C., Terraza M., (2003): It is possible to study chaotic and ARCH behaviour jointly? Application of a noisy Mackey-Glass equation in the Paris Stock Exchange returns series, Computational Economics, 21, pp. 257-276.

[17] Kyrtsou C, Terraza V., (2003): Evidence for mixed non-linearity in daily stock exchange series, Political Economy, 13, pp. 71-97.

[18] Lopez J.A (1998): Methods for evaluating value at risk estimates, Working Paper, Federal reserve bank of New York \#9802.

[19] Mackey M, Glass L., (1977): Oscillation and chaos in physiological control systems, Science, 50, pp 287-289

[20] Mcleod, A.I., Li, W.K., (1983): Diagnostic checking ARMA time series models using squared-residuals autocorrelations, Journal of Time Series Analysis, 4, pp. 269-273.

[21] Pafka S, Kondor I (2001): Evaluating the riskmetrics methodology in measuring volatility and value at risk in financial markets, Working Paper, March 2001.

[22] Terraza V., (2002): Modélisations de la Value at Risk du CAC 40. Un essai d'amélioration de l'approche RISKMETRICS par la modélisation hétéroscédastique saisonnière. Actes de Colloque Journée d'économétrie de Paris X Nanterre, April 2002.

[23] Terraza V., (2002): Modélisations de la Value at Risk, une évaluation de l'approche Riskmetrics, Thèse de Doctorat, université Paris 2.

[24] Theiler J., Eubank S., Longtin A., Galdrikian B., Farmer D., (1992): Testing for nonlinearity in time series: the method of surrogate data, Physica D, 58, pp. 77-94

[25] Tsay R.S., (1986): Nonlinearity tests for time series, Biometrica, 73, pp. 461-466.

[26] White, H., (1989): Some asymptotic results for learning in single hidden layer feedforward networks models, Journal of the American Statistical Association, Vol. 84, pp. 1003-1013. 